\title{
A scanning electronmicroscopy investigation of the structure of colonies of different morphologies produced by phenotypic switching of Candida albicans
}

\author{
D. R. RADFORD, S. J. CHALLACOMBE* and J. D. WALTER
}

\author{
Departments of Prosthetic Dentistry and * Oral Medicine and Pathology, UMDS, Guy's Dental Hospital, \\ London SE1 9RT
}

\begin{abstract}
Summary. Variant colony formation by Candida albicans has been described and the phenomenon of phenotypic switching has been studied extensively. Whereas the microstructure of non-variant colonies has been investigated by scanning electronmicroscopy (SEM), the relationship between switched variant colonies and microstructure has not been described. The object of this study was to investigate and compare by SEM the microstructure of the normal colony type and five common variant colony types of $C$. albicans and to determine whether a pattern of dimorphic growth could account for the characteristic colony morphologies. A general relationship between colony type and structure was observed; smooth colonies consisted entirely of blastospores whereas regular, irregular-wrinkled and semi-rough colonies consisted of different proportions of true hyphae and blastospores. Regular extreme-jagged shaped colonies consisted of an almost pure culture of pseudohyphae, and colonies producing aerial hyphae were composed of pseudo- and true hyphae, as well as blastospores. These results show a clear relationship between colony morphology and development of particular cell types.
\end{abstract}

\section{Introduction}

Candida albicans is an asexual diploid fungus. Although it is a common commensal, it is also an important opportunist pathogen causing a wide spectrum of diseases in man. ${ }^{1}$ Most recently, oral candidiasis has been studied extensively because of its association with immunocompromised individuals. ${ }^{2,3}$

The potential of $C$. albicans to form variant colonies is well known $\mathrm{k}^{4,5}$ and, originally, three main colony forms were described ${ }^{4}$ although a further 17 rough/ hairy colony types were added later. ${ }^{6}$ Additional types have been described as a result of high frequency phenotypic switching induced by ultraviolet irradiation. ${ }^{7,8}$ High frequency switching of $C$. albicans was first described in cultures of the standard laboratory strain $3153 \mathrm{~A}^{8}$ on Candida Agar. ${ }^{9}$ The medium contains amino acids, salts, vitamins and glucose and was developed to investigate the aminopeptidase profile of C. albicans. ${ }^{10,11}$ More recently, 384 different colonial morphologies, probably representing naturally occurring switching, have been claimed, ${ }^{12}$ although only 5-8 variant colony types are reported commonly.

Despite recent work on DNA fingerprinting of phenotypically switched variant colonies, ${ }^{9,12,13}$ little information is available concerning the microstructure of individual colonies. ${ }^{14,15}$ Scanning electronmicro-

Received 6 July 1993; revised version accepted 10 Dec. 1993. scopy (SEM) studies have indicated that rough colonial variants were composed of a large number of pseudo-hyphal cells, although this was described for only one colony and little detail was presented. ${ }^{14}$

The aim of this study was to investigate the structural composition of the normal and five variant colony types by SEM and to relate characteristic colony morphology to patterns of dimorphic cell development.

\section{Materials and methods}

\section{Culture technique}

C. albicans strain $3153 \mathrm{~A}$ was obtained as a stock culture from the Commonwealth Mycological Institute, Kew, London. Identification was confirmed by germ-tube formation, in bovine serum and with the API 20C Aux system (bioMérieux, Basingstoke).

A loopful of a single colony from Sabouraud's Agar was added to $10 \mathrm{ml}$ of sterile normal saline and dispersed with a mechanical vibrator. Cells were counted in a haemocytometer (modified FuchsRosenthal) and the suspension was adjusted to give a final concentration of $10^{5}$ cells $/ \mathrm{ml}$. Candida Agar without zinc supplement ${ }^{10,12}$ was inoculated with $100 \mu \mathrm{l}$ of the suspension to give a density of $c .100$ cells/plate and incubated for 14 days at $25^{\circ} \mathrm{C}$. Colonies with normal morphology, together with five variants, 

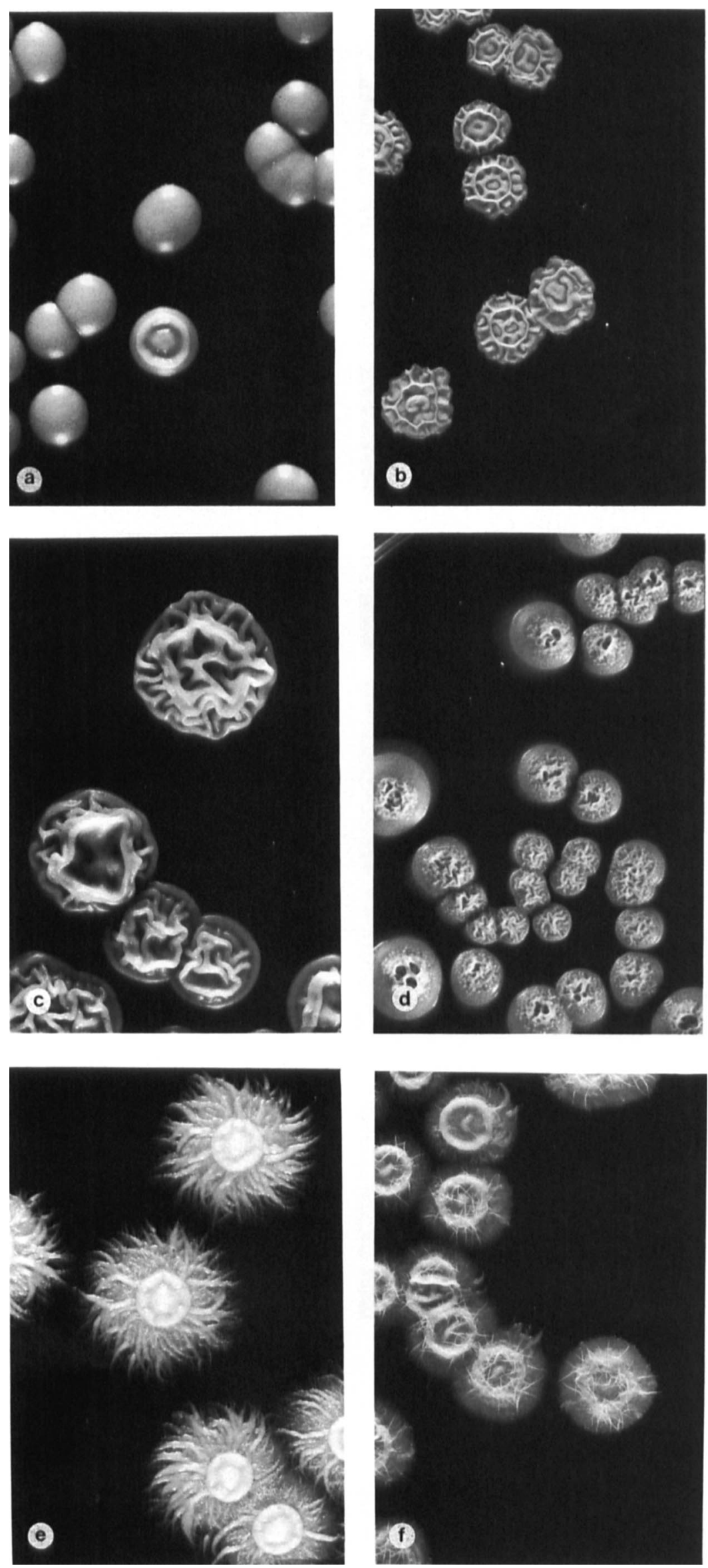

Fig. 1. The appearance of the six colony type of C. albicans 3153A: a, 'o' smooth, with a single switched colony; b, regular-wrinkled colony; c, irregular-wrinkled colony; $d$, semi-rough type with a highly wrinkled centre but with a smooth periphery; $\mathbf{e}$, regular extreme-jagged; $\mathbf{f}$, fuzzy type with aerial hyphae $($ all $\times 5$ ). 

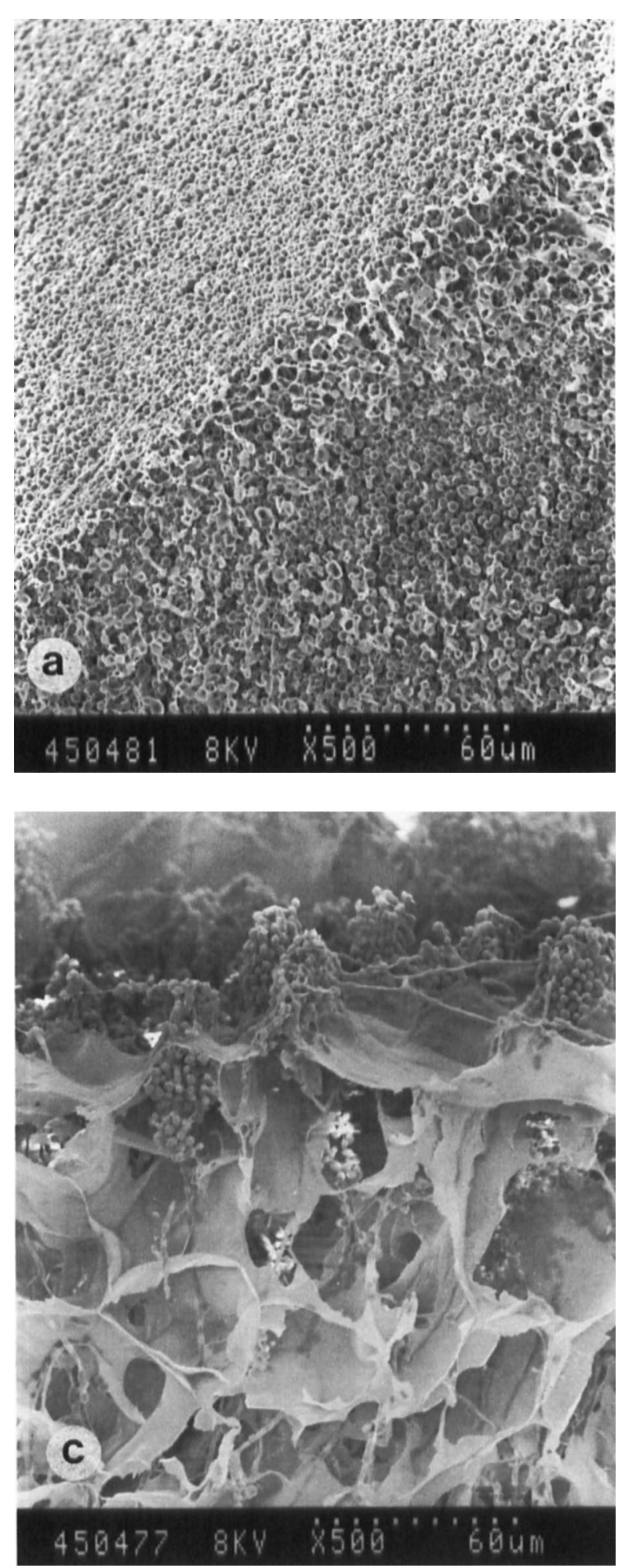

were selected and were subcultured sequentially up to eight times under the same conditions. Colonies whose morphology remained stable over this period were then selected for SEM examination and their biochemical characteristics were re-confirmed with API 20C Aux. Colonies were photographed with a standard SLR camera and monochrome film $(\times 10$ original magnification; Kodak T-Max, Kodak Ltd, Hemel Hempstead).

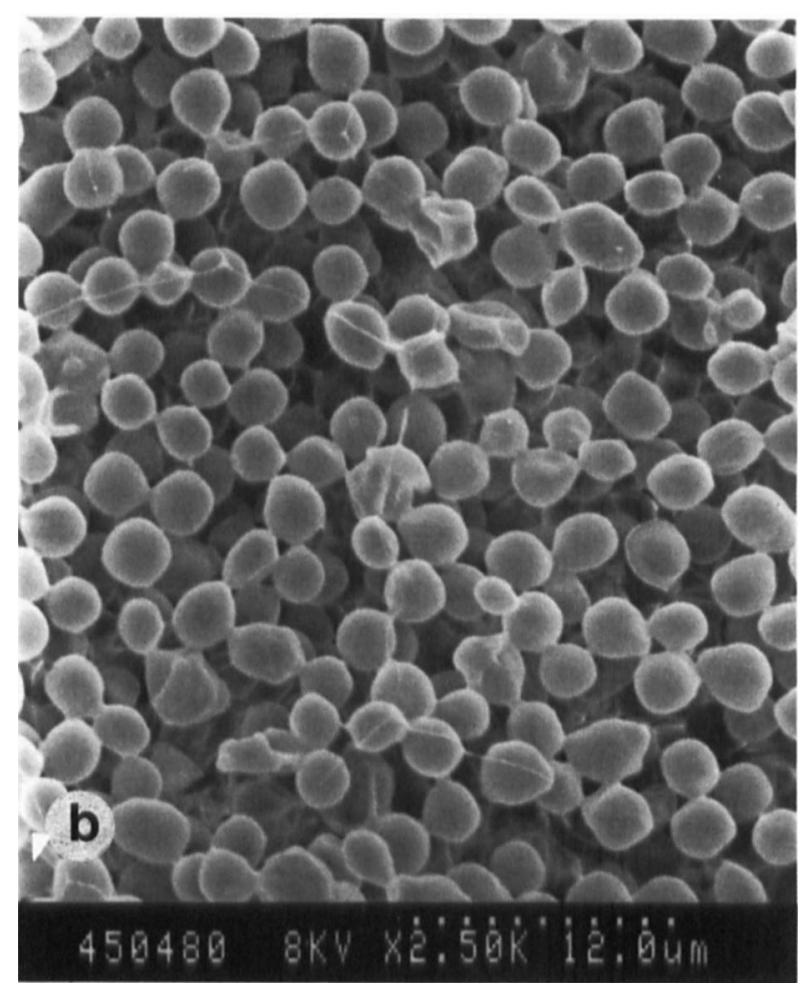

Fig. 2. SEMs of normal 'o' smooth colonies of C. albicans 3153A: a, the surface and the body of the colony consists entirely of blastospores $(x 455) ; \mathbf{b}$, the under-surface of a colony that has become detached from the agar shows budding blastospores and a fine filamentous network $(\times 2275)$; , chains of blastospores growing into the agar which appears honeycombed due to dehydration $(\times 455)$.

\section{Preparation for scanning electronmicroscopy}

A scalpel blade was used to remove a whole yeast colony including $5 \mathrm{~mm}$ of the surrounding agar from the culture plate. The sample was plunged into liquid nitrogen, frozen for $2 \mathrm{~min}$, then removed carefully and placed on a pre-cooled stainless steel dissection plate. The sample was manually impact fractured with a scalpel blade in the centre of the air interface surface of a colony. Previous pilot studies had shown that a fracture which started from the undersurface of the 

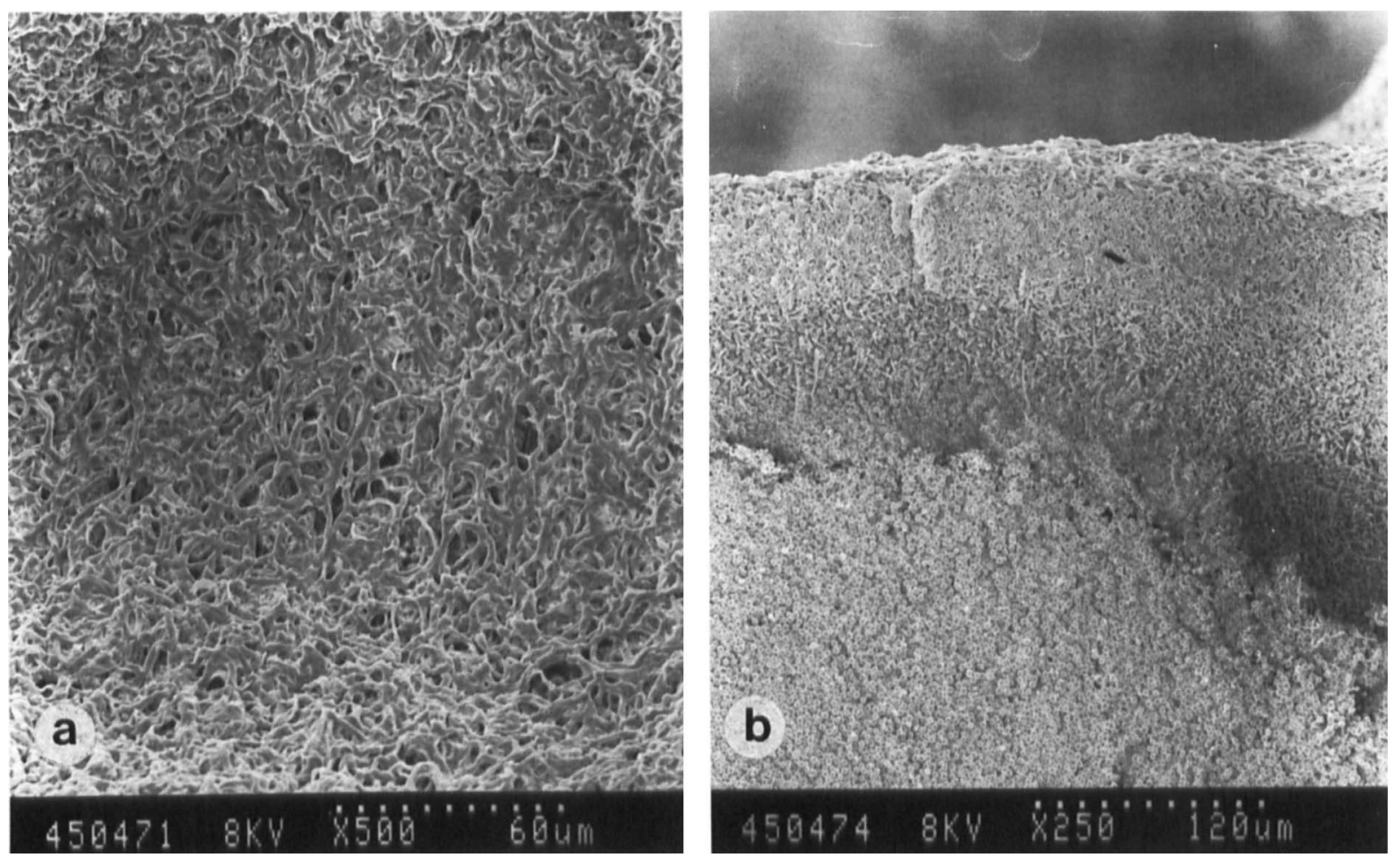

Fig. 3. SEMs of regular-and irregular-wrinkled colonies of C. albicans $3153 \mathrm{~A}: \mathbf{a}$, the surface of a colony showing a complex mass of fused and matted true hyphae with very few blastospores $(\times 455)$; $\mathbf{b}$, a cross-section through the surface of a colony-the top 60-100 $\mu \mathrm{m}$ is composed of matted hyphae, the next $20-30 \mu \mathrm{m}$ is a mixture of hyphae and blastospores, and the body consists entirely of blastospores $(\times 230)$.

agar resulted in obliteration of the colony. Fracture of a colony normally resulted in three or four individual samples which were placed in an Edwards Pearce Tissue Drier, EPD 3 (Edwards High Vacuum International, Crawley) for $8 \mathrm{~h}$. The samples were stored in a desiccator for not more than $48 \mathrm{~h}$ before being mounted on to aluminium stubs with silver colloidal paint (Agar Scientific Ltd, Stanstead). Stubs were coated with gold (Emsope SC5000 Sputter Coater, Emitech, Ashford) and viewed by SEM (Hitachi S520 , Hitachi plc, Wokingham) at either $8 \mathrm{kV}$ or $10 \mathrm{kV}$. Five colonies of each representative colony type were viewed and photographed (Kodak Plus-X 120 roll film, Kodak Ltd).

\section{Results}

\section{Cultural types}

The colonies investigated were the normal ' $\mathrm{O}$ ' smooth type, regular-wrinkled, irregular-wrinkled and semi-rough (wrinkled centre and a smooth periphery) types, regular extreme-jagged morphology (with an undulating centre) and a fuzzy form that produced aerial hyphae (fig. 1a-f).

\section{Normal ' $o$ ' smooth colonies}

The impact fractured sections from the top, under- surface and body of colonies of normal ' 0 ' smooth morphology were composed entirely of blastospores (fig. 2a). The under-surface of a smooth colony which had become detached from the agar showed blastospores of $4 \mu \mathrm{m}$ in diameter. Cells were budding and this, together with a thin network of communicating filaments, gave the impression of chains of cells (fig. $2 b)$. When the body of the agar was viewed, a thin honeycomb due to desiccation was present and chains of blastospores were noted within the matrix of the agar to a depth of $300 \mu \mathrm{m}$ (fig. 2c).

\section{Regular-and irregular-wrinkled colonies}

The surface of regular- and irregular-wrinkled colonies were composed almost entirely of branched hyphal cells with very few blastospores. It was difficult to categorise the cells as pseudo- or true hyphae (fig. 3a). The surface of elevated ridges of both regular- and irregular-wrinkled colonies consisted of only hyphal cells with isolated islands of blastospores (not illustrated). The sectioned surfaces of the periphery of these colonies were less wrinkled and showed a remarkable transition from a nearly pure population of hyphal cells at the colony surface to almost pure blastospores in the centre. The top $60 \mu \mathrm{m}$ consisted of hyphal cells, the next $40 \mu \mathrm{m}$ of hyphal and blastospore forms and the body of the colony of blastospores only (fig. 3b). 

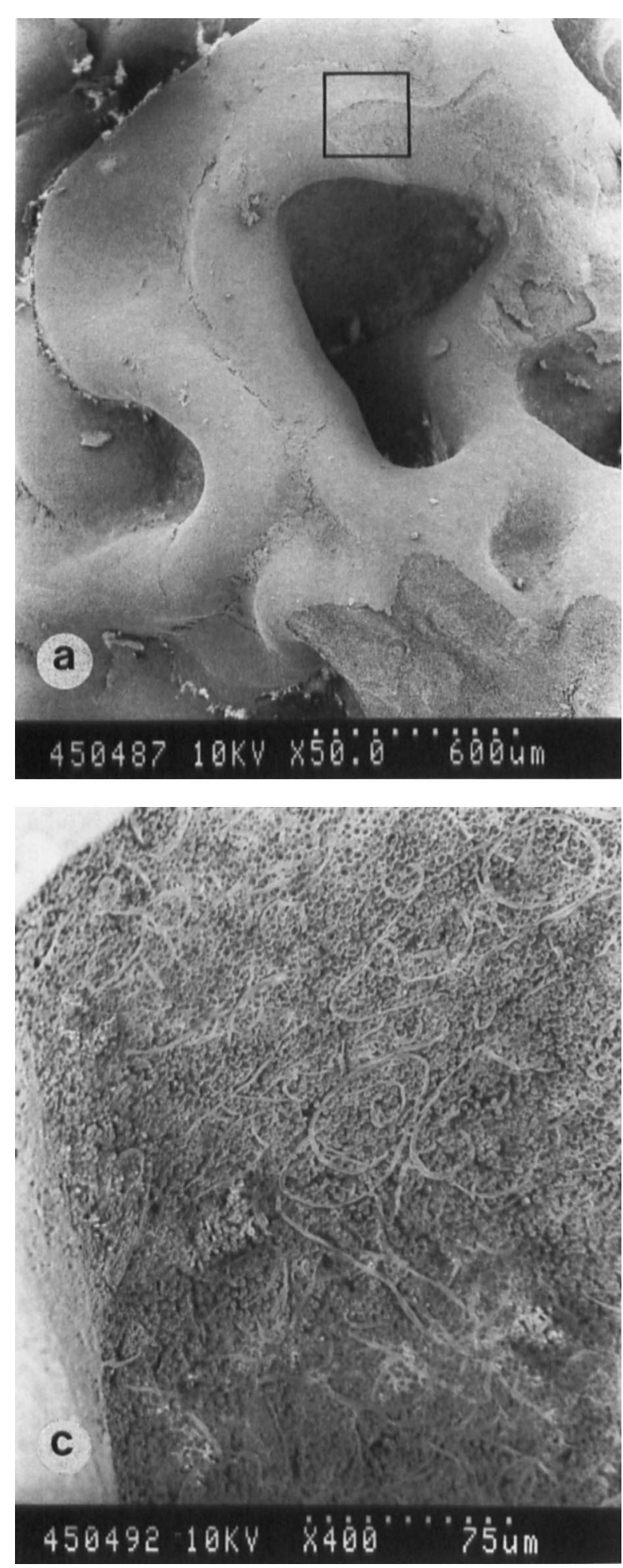

\section{Semi-rough colonies}

Semi-rough colonies consisted of blastospores and true hyphae but in different proportions and patterns of development from those reported for wrinkled colonies. Fig. 4a illustrates the whole of an elevated wrinkle at low magnification; fig. $4 \mathrm{~b}$ is a view of an elevated portion and fig. $4 \mathrm{c}$ a view from toward the bottom of the central depression illustrated in fig. 4a. The elevated wrinkles were covered by blastospores, whereas the body consisted of approximately equal numbers of hyphal cells and blastospores. Some

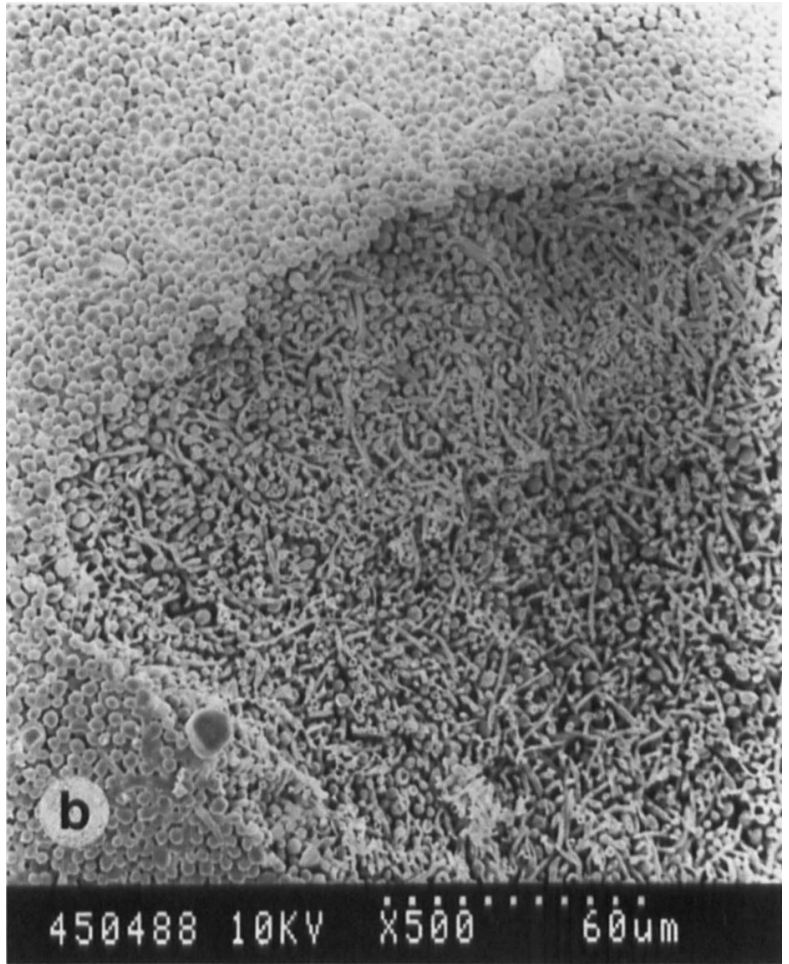

Fig. 4. SEMs of the wrinkled centre portion of a semi-rough colony of $C$. albicans $3153 \mathrm{~A}: \mathbf{a}$, the wrinkled centre area shows the fractured site illustrated in $\mathbf{b}$ (see box) and the base of the central depression demonstrated in $\mathbf{c}(\times 45) ; \mathbf{b}$, the surface shows a predominance of blastospores with some hyphal cells, the body of the colony consists of blastospores and hyphae but with no obvious transition zone as shown in fig. 3b $(\times 455)$; c, the surface is composed mainly of blastospores but exceedingly long hyphal cells $(75-100 \mu \mathrm{m})$ are on the surface $(\times 365)$.

exceedingly long hyphal cells (at least $100 \mu \mathrm{m}$ in length) were observed in the depressions on the surface of the colonies. The hyphal cells were interpreted as true hyphal forms rather than pseudo-hyphal forms, as constrictions between cells were either not evident or only very slightly apparent. ${ }^{1}$ The smooth periphery of this colony type consisted entirely of blastospores (not illustrated).

\section{Regular extreme-jagged colonies}

The undulating centres and the whole surface and 

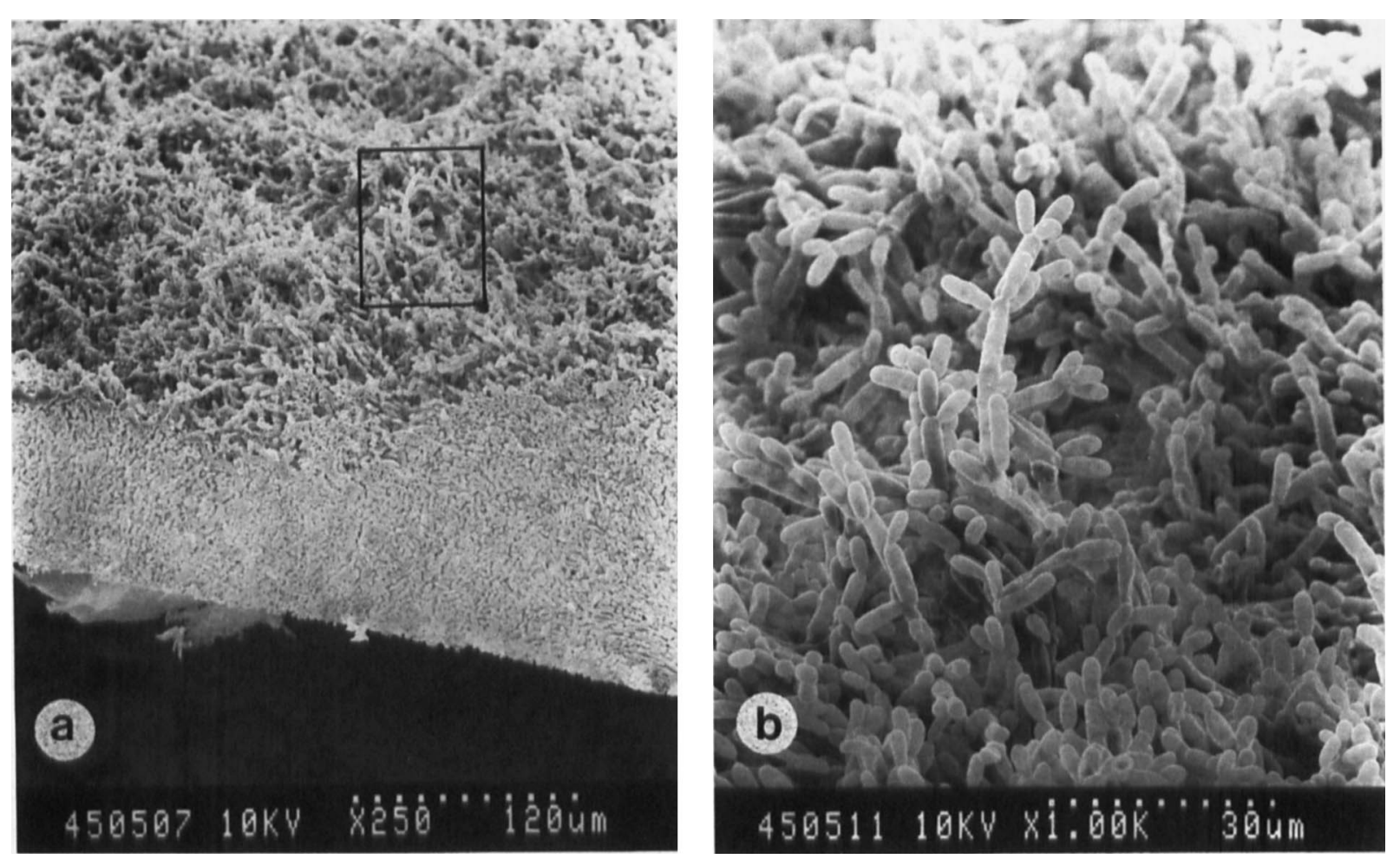

Fig. 5. SEMs of a regular extreme-jagged colony of C. albicans $3153 \mathrm{~A}: \mathbf{a}$, a horizontal section is through a complete colony where the nutrient agar has become detached-the whole thickness of the colony is composed of pseudo-hyphal cells $(\times 230)$; $\mathbf{b}$, the surface of the colony $(\mathbf{a}$, box $)$ has pseudo-hyphal cells growing away from its surface $(\times 900)$.
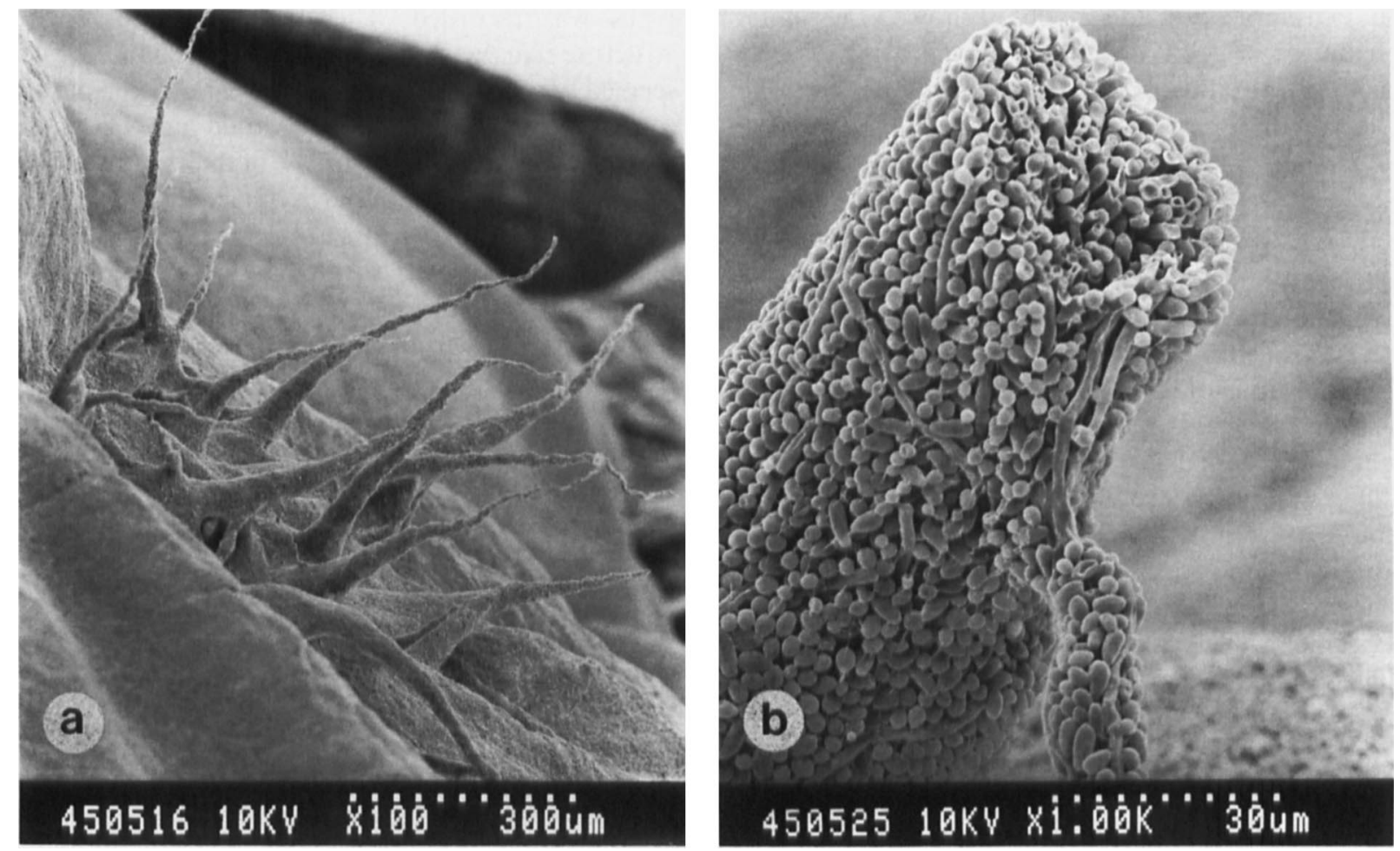

Fig. 6. SEMs of fuzzy type colonies of C. albicans 3153A that produce aerial hyphae: a, the surface of the colony undulates with a discrete area producing aerial hyphae $(\times 90)$; b, an aerial hypha that has been truncated in preparation--this is composed of blastospores and true and pseudo-hyphae; two aerial hyphae can be seen merging but the truncated areas shows no evidence of a cored structure; the fine filamentous structure described in fig. $\mathbf{2 b}$ is present $(\times 900)$.

body of the regular extreme-jagged colonies consisted entirely of pseudo-hyphal cells (figs. $5 \mathrm{a}$ and b). Chains of cells were growing away from the body of the colony (fig. 5 b). This was a significantly different pattern of growth from the other colony types, where a mixture of true hyphae and blastospores developed and covered the surfaces. 
Table. Cell types present in colonies of different morphologies

\begin{tabular}{|c|c|c|c|}
\hline \multirow{2}{*}{ Colony type } & \multicolumn{3}{|c|}{$\begin{array}{c}\text { Cell types present as a percentage } \\
\text { of the total }\end{array}$} \\
\hline & blastospores & true hyphae & pseudohyphae \\
\hline 'o' Smooth & 100 & $<1$ & $<1$ \\
\hline Regular-wrinkled & 80 & 20 & $<1$ \\
\hline Irregular-wrinkled & 80 & 20 & $<1$ \\
\hline Semi-rough & 50 & 50 & $<1$ \\
\hline $\begin{array}{l}\text { Regular extreme- } \\
\text { jagged }\end{array}$ & $<1$ & $<1$ & 100 \\
\hline Aerial hyphae & 40 & 40 & 20 \\
\hline
\end{tabular}

\section{Colonies with aerial hyphae (fuzzy type)}

Aerial hyphae were found in discrete areas of the undulating surface of fuzzy colonies. At their base aerial hyphae were up to $150 \mu \mathrm{m}$ thick, tapering to 6-8 $\mu \mathrm{m}$ at their extremities, and $600 \mu \mathrm{m}$ in length (fig. $6 a)$. Examination at $\times 1000$ showed that some hyphae had been truncated during preparation (fig. $6 \mathrm{~b}$ ), thus allowing a cross-section to be studied. This consisted of blastospores, pseudo-hyphae and true hyphae. Also, some aerial hyphae appeared to have merged during growth (fig. $6 \mathrm{~b}$ ). There was no evidence of a core of one cell type surrounded by other cell types. The extremities of the hyphae showed a similar distribution of cell types to that at the bases of these structures (not illustrated).

\section{Discussion}

The current study investigated six commonly occurring colony morphologies that remained stable for several sequential growth cycles. Although rough colonial forms of $C$. albicans have been described for over 60 years, recently 384 different naturally occurring colonial forms have been reported for C. albicans 3153A growing on Candida Agar. ${ }^{13}$ The colonies were not induced by ultraviolet irradiation and this differed from earlier studies in which phenotypic switching was induced by ultraviolet radiation of unspecified wavelength, duration and density. ${ }^{8}$

The results showed considerable differences between the colonies investigated. There was a definite relationship between colony shape and the constituent cells (table). Many of the colonies, at high magnification, exhibited a fine matrix that intercommunicated between cells and has been reported previously in the superficial cells from a washed colony of C. parapsilosis. ${ }^{15}$ This intercellular matrix has been described in some detail and is present only when yeasts are grown on agar. ${ }^{16}$ Odds $^{1}$ speculated that the matrix is an accretion of fibrillar material derived from the outer cell-wall coat. An alternative possibility is that it is an accretion associated with the pattern of growth.
Cells were observed growing into the agar as irregular chains. This differs from previous reports which concluded that, due to the separation of the agar from the colony during freeze drying, cells do not grow into the matrix and grow only on the surface. ${ }^{15}$

Surface wrinkling of the regular- and irregularwrinkled colonies may be explained by the development of surface hyphal cells. The mass of hyphal cells would require to grow at a greater rate than the blastospores, even though these surface cells were furthest from the nutrient source. However, this does not explain why the surfaces of the centre of the semirough colony types did not show a well demarcated layer of fused hyphal cells.

The regular extreme-jagged shaped colonies differed from all the other variant colonies studied in that they were composed of a nearly pure culture of pseudohyphae. The only other example of colonies that consisted of a single cell type (blastospores) was the ' 0 ' smooth form.

It might have been expected that examination of aerial hyphae to indicate the stages in growth of agargrown $C$. albicans would have revealed a pattern consisting of a core of hyphal cells with blastospores and pseudo-hyphal cells developing around that core. However, no such arrangement was found and, instead, an apparently haphazard collection of all cell types was recorded. The development of such a structure remains difficult to explain, as daughter cells seemed to be growing away from the nutrient source at a considerably faster rate than would have occurred if they had spread over the surface of the existing colony. The development of aerial hyphae definitely shows that the colony also grows at the air interface and not just close to the agar surface as has been described previously. ${ }^{15}$ It is possible that there may be some integration of the different cell types of $C$. albicans to form such complex structures.

The pathogenicity of C. albicans is associated with a number of factors, including adherence to the host cell $1{ }^{17}$ and high frequency switching. ${ }^{18,19}$ Our findings suggest that, in vitro, C. albicans can produce a number of different colony types that appear to be related to combinations of the three main morphological forms of the yeast cells. This study demonstrated that the shape of smooth and rough colonies was related to the presence of hyphal cell forms. It is not clear whether this altered ratio of cellular constituents in vitro may be associated with the pathogenicity of isolates in a high frequency switching mode at sites of infection. The relationship of blastospores, true and pseudo-hyphae is complex and depends upon the shape of the switched colony, but, nevertheless, may help elucidate the relationship between pathogenicity in vivo and colonial morphology in vitro.

We acknowledge the help of L. Fernandes and Dr K.C. Rajasingham of the Department of Oral Medicine and Pathology, and K. Brady of the E.M. Unit, Guys Campus, UMDS, for technical assistance. 


\section{References}

1. Odds FC. Candida and candidosis, 2nd edn. London, Bailliere Tindall. 1988.

2. Klein RS, Harris CA, Small CB et al. Oral candidiasis in high risk patients as the initial manifestation of the acquired immunodeficiency syndrome. $N$ Engl J Med 1984; 311 : $354-358$.

3. Challacombe SJ. Revised classification of HIV-associated oral lesions. $B$ Dent $J 1991$; 170 : 305-306.

4. Mackinson JE. Dissociation in Candida albicans. $J$ Infect Dis 1940; 66: 59-77.

5. Di Menna ME. Natural occurrence of rough variant of a yeast, Candida albicans. Nature 1952; 169: 550-551.

6. Brown-Thomsen J. Variability in Candida albicans (Robin) Berkhout. I. Studies on morphology and biochemical activity. Hereditas $1968 ; 60$ : 355-398.

7. Pomés R, Gil C, Nombela C. Genetic analysis of Candida albicans morphological mutants. J Gen Microbiol 1985; 131 : $2107-2113$.

8. Slutsky B, Buffo J, Soll DR. High-frequency switching of colony morphology in Candida albicans. Science 1985; 230 : 666-669.

9. Anderson JM, Soll DR. Unique phenotype of opaque cells in the White-Opaque Transition of Candida albicans. $J$ Bacteriol 1987; 169: 5579-5588.

10. Lee KL, Buckley HR, Campbell CC. An amino acid liquid synthetic medium for the development of mycelial and yeast forms of Candida albicans. Sabouraudia 1975; 13: 148-153.

11. Lee KL, Rega ME, Watson RR et al. Identification of yeast phase of pathogenic fungi by the specificity of their aminopeptidases. Sabouraudia 1975; 13: 132-141.

12. Rustchenko-Bulgac EP, Sherman F, Hicks JB. Chromosomal rearrangements associated with morphological mutants provide a means for genetic variation of Candida albicans. $J$ Bacteriol 1990; 172: 1276-1283.

13. Suzuki T, Kobayashi I, Kanbe T, Tamaka K. High frequency variation of colony morphology and chromosome reorganization in the pathogenic yeast Candida albicans. $J$ Gen Microbiol 1989; 135 : 425-434.

14. Joshi KR, Gavin JB. The morphology of colony variants of three species of Candida. Sabouraudia $1975 ; 13: 274-279$.

15. Whittaker DR, Drucker DB. Scanning electron microscopy of intact colonies of microorganisms. J Bacteriol 1970; 104 : 902-909.

16. Joshi KR, Gavin JB, Armiger LC. Intercellular matrix in colonies of Candida. J Bacteriol 1975; 123: 1139-1143.

17. Douglas LJ. Adhesion of pathogenic Candida species to host surfaces. Microbiol Sci 1985; 2: 243-247.

18. Soll DR, Langtimm CJ, McDowell J, Hicks J, Galask R. Highfrequency switching in Candida strains isolated from vaginitis patients. J Clin Microbiol 1987; 25: 1611-1622.

19. Soll DR, Galask R, Isley $\mathbf{S}$ et al. Switching of Candida albicans during successive episodes of recurrent vaginitis. $J$ Clin Microbiol 1989; 27: 681-690. 